\title{
IMMUNE RESPONSE TO DNA VACCINE EXPRESSING TRANSFERRIN BINDING PROTEIN A GENE \\ OF PASTEURELLA MULTOCIDA
}

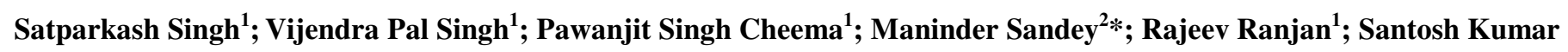 Gupta $^{1}$; Bhaskar Sharma ${ }^{3}$}

${ }^{1}$ Division of Bacteriology \& Mycology, Indian Veterinary Research Institute, Izatnagar-243122, India; ${ }^{2}$ Scotch Ritchey Research Center, Auburn University, Auburn-36849, Alabama, USA; ${ }^{3}$ Division of Animal Biochemistry, Indian Veterinary Research Institute, Izatnagar-243122, India.

Submitted: April 24, 2010; Approved: January 13, 2011.

\begin{abstract}
Haemorrhagic Septicaemia (HS), an acute and fatal disease of cattle and buffalo is primarily caused by serotype B:2 or E:2 of Pasteurella multocida. The transferrin binding protein A (TbpA) has been found to act as immunogen and potent vaccine candidate in various Gram negative bacteria including P. multocida. The present study was carried out to evaluate the potential of this antigen as a DNA vaccine against HS in mice model. The tbpA gene of $P$. multocida serotype B:2 was cloned in a mammalian expression vector alone and along with murine IL2 gene as immunological adjuvant to produce monocistronic and bicistronic DNA vaccine constructs, respectively. The immune response to DNA vaccines was evaluated based on serum antibody titres and lymphocyte proliferation assay. A significant increase in humoral and cell mediated immune responses was observed in mice vaccinated with DNA vaccines as compared to non immunized group. Additionally, the bicistronic DNA vaccine provided superior immune response and protection level following challenge as compared to monocistronic construct. The study revealed that DNA vaccine presents a promising approach for the prevention of HS.
\end{abstract}

Key words: DNA vaccine, Haemorrhagic septicaemia, IL2, Pasteurella multocida, Transferrin binding protein

\section{INTRODUCTION}

Pasteurella multocida, a Gram negative coccobacillary organism is responsible for a number of diseases in livestock and poultry such as Haemorrhagic Septicaemia (HS) in cattle and buffalo, atrophic rhinitis in pigs, pneumonia in sheep and fowl cholera in poultry. Among these, HS is an important disease prevalent in South East Asian countries where it remains of a considerable economic importance (31). Various vaccine preparations like alum precipitated, oil adjuvant 
vaccine $(\mathrm{OAV})$ and genetically modified mutant vaccine being used against HS in India and other parts of world have certain demerits like short term immunity, difficulty in administration or reversion to virulent form $(3,10,31,38)$.

Structural components of $P$. multocida such as capsule and outer membrane proteins have been identified as potent immunogens for the development of safe and effective vaccines $(21,25)$. Similarly, outer membrane proteins involved in acquisition of iron from the host i.e., iron regulated outer membrane proteins (IROMPs) have also been targeted as vaccine candidates (7). IROMPs are infact, transferrin binding proteins usually expressed by bacteria inside host body in response to iron depleted conditions and their in vitro expression is enhanced by the addition of iron chelators like 2, 2'-dipyridyl in the culture media (30). Amongst these proteins, TbpA, a transferrin receptor in bovine strains of $P$. multocida considered to act as a channel for transport of iron across the outer membrane has been designated as one of the prime immunogens of the organism (19). Veken et al. (32) has reported the association of transferrin binding proteins with HS causing strains of $P$. multocida in bovine whereas the strains of non HS serotypes failed to express this protein. Consequently, it was suggested to be one of the factors responsible for the virulence of HS causing strains of $P$. multocida.

Currently, DNA vaccines are a subject of investigation in the field of vaccine research primarily due to their ability to induce de novo production of antigens in the similar manner as that of live vaccines. These vaccines effectively induce strong and long lasting immune responses by generating both humoral and cell mediated immunity along with the stimulation of immunological memory $(4,15)$. Different cytokines including interferon (2), granulocyte macrophage colony stimulating factor (23) and interleukins (35) have been used as adjuvants to improve the immune response against primary immunogens. Interleukin 2 (IL-2) is reported to act as an immunomodulator in DNA vaccines that activates multiple compartments of immune system including helper $\mathrm{T}$ cells, cytotoxic $\mathrm{T}$ cells, B cells, macrophages and NK cells (5). The present investigation was carried out to assess the efficacy of $t b p A$ gene alone and in combination with $I L-2$ gene as DNA vaccines against $P$. multocida serotype B:2 in mice.

\section{MATERIALS AND METHODS}

\section{Primers}

Different primers used in the study were designed taking into account their reported sequences (accession numbers: AJ558182, X01772). The sequences of various oligonucleotides with restriction sites (underlined) for respective enzymes were as:

tbpA Forward - 5'-

ACTCGAGATGCTTACTTTAGTCTTTAGTG-3'

XhoI

tbpA Reverse- 5'-

AACGCGTCTAAAAACGAATTTCCACCGAGG-3'

MluI

IL-2 Forward- 5'-

CCTGTCGACATGTACAGCATGCAGCTCG-3'

SalI

IL-2 Reverse- 5' -

AGGTGCGGCCGCTTATTGAGGGCTTGTTGA-3'

Not $\mathrm{I}$

\section{Amplification of the $\operatorname{tbp} A$ gene}

Genomic DNA from P. multocida serotype B:2 (strain P52) was used as template for the amplification of $t b p A$ gene. The PCR mixture consisting of $50 \mathrm{ng}$ of template, $25 \mathrm{pmol}$ of each of the forward and reverse primers (Integrated DNA Technologies, Inc, IA, USA), $200 \mu \mathrm{M}$ of each of the dNTPs, 1x PCR buffer, $1.5 \mathrm{mM} \mathrm{MgCl}_{2}$ and $1 \mathrm{U}$ of Taq DNA polymerase (MBI fermentas, USA) was made into $25 \mu 1$ volume with nuclease free water (Bangalore Genei, India). PCR program was performed with the initial denaturation at $94^{\circ} \mathrm{C}$ for $5 \mathrm{~min}$ followed by 30 cycles of denaturation at $94^{\circ} \mathrm{C}$ 
for $30 \mathrm{sec}$, annealing at $60^{\circ} \mathrm{C}$ for $45 \mathrm{sec}$, extension at $72^{\circ} \mathrm{C}$ for $2 \mathrm{~min}$ and a final extension at $72^{\circ} \mathrm{C}$ for $10 \mathrm{~min}$.

\section{Amplification of $I L 2$ gene from murine splenocytes}

The total RNA from splenocytes cultured in presence of concanavalin A (ConA) $(10 \mu \mathrm{g} / \mathrm{ml})$ (Bangalore Genei, India) was isolated using RNA isolation kit (Qiagen, CA) as per the manufacturer's recommendations. The cDNA was synthesized by reverse transcription (RT) using first strand cDNA synthesis kit (MBI fermentas, USA) and the IL2 gene was PCR amplified using this cDNA as template.

\section{Construction of recombinant plasmids and their confirmation}

For cloning of the target genes, pIRES mammalian expression vector (Clontech, BD Biosciences) having two multiple cloning sites (MCS) under two different promoters was employed. The MCS-A is transcribed under the cytomegalovirus promoter where as MCS-B is under the internal ribosome entry site (IRES) promoter of encephalomyocarditis virus (Fig. 1). The amplicons and pIRES vector were digested with respective restriction enzymes (MBI Fermentas, USA) and the digested products were gel eluted using Mini Elute Gel extraction kit (Qiagen, CA). The $t b p A$ gene was cloned between $\mathrm{XhoI}$ and $M l u \mathrm{I}$ restriction enzyme sites in MCS-A of pIRES vector to produce plasmid construct pIRES-tbpA whereas the IL2 gene was cloned between SalI and NotI sites in MCS-B of recombinant pIRES-tbpA to generate pIRES-tbpA-IL2 (Fig. 1). Both the recombinant plasmids were separately transformed into E. coli DH5a (Promega, Madison) competent cells. The resulting clones were grown in Luria Bertani broth (Himedia, India) containing $100 \mu \mathrm{g} / \mathrm{ml}$ ampicillin overnight and plasmid DNA was isolated using Miniprep kit (Qiagen, CA). Finally, the plasmids were confirmed for the presence of desired insert by restriction enzyme analysis.
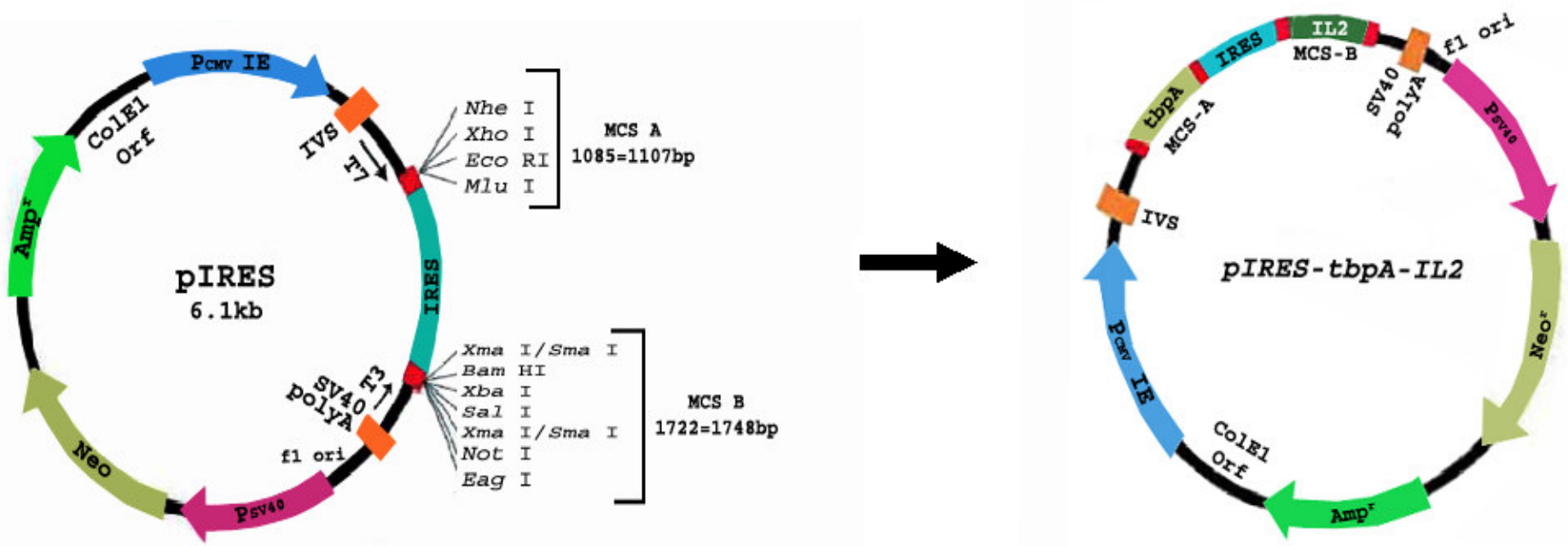

Figure 1. Schematic representation of $t b p A$ and $I L 2$ genes in recombinant plasmid pIRES-tbpA-IL2. 


\section{Expression analysis of recombinant plasmids}

For the in vitro expression analysis of $t b p A$ gene, MadinDarby canine kidney (MDCK) cells were transfected with DNA vaccine construct pIRES-tbpA or pIRES vector alone. The purified DNA (1.5 $\mu \mathrm{g} /$ well) was used for transfection of MDCK cells seeded in 6 well plates using Polyfect reagent (Qiagen, CA) as per the manufacturer's protocol. The cells were subjected to indirect fluorescent antibody test (IFAT) 72 hr post transfection using monospecific polyclonal antisera (1:25 dilution) raised against recombinant pIRES-tbpA in swiss albino mice and anti-mouse IgG FITC conjugate (1:200 dilution). Finally, the cells were overlaid with $50 \%$ glycerol and examined under fluorescent microscope (Nikon microphot, Japan).

\section{Immunization of mice}

The plasmid DNA was isolated in bulk to be used for immunization using endotoxin free plasmid purification kit (Qiagen, CA). Healthy swiss albino female mice, weighing around 18-20 gm obtained from the Laboratory Animal Resource Section, IVRI, Izatnagar were maintained under standard conditions of nutrition and management. Mice randomly distributed into various groups of eighteen each were immunized intramuscularly with a dose of $100 \mu \mathrm{g}$ of plasmid DNA vaccine constructs and boosted on $14^{\text {th }}$ day. The groups were categorized as Group I, II, III, IV and V receiving pIREStbpA, pIRES-tbpA-IL2, oil adjuvant vaccine (OAV), pIRES vector and PBS, respectively, as primary as well as booster dose. Another group (VI) was administered primary vaccination with pIRES-tbpA-IL2 and boosted with OAV. The serum samples were collected from the immunized mice at 0 , 14, 28 and 35 days post vaccination. Subsequently, three sera in each group were pooled to form six pooled serum samples per group.

\section{Evaluation of immune response}

Mice sera collected at different intervals were subjected to enzyme linked immunosorbent assay (ELISA) using sonicated antigen $(5 \mu \mathrm{g} / \mathrm{ml})$ prepared by growing the bacterial cells in brain heart infusion broth medium (Difco, France) supplemented with $50 \mu \mathrm{M}$ 2, 2'-dipyridyl (Himedia, India). Rabbit anti-mouse IgG-Horse radish peroxidase (HRPO)/IgG1HRPO/IgG2a-HRPO (1:5000 dilution) was used as conjugate. Standardization of optimum concentration of reactants was carried out using checker board method (12) and the reactions were carried out in duplicate. The absorbance was measured at 492 nm using ELISA reader (Multiscan EX, Labsystems).

The cell-mediated immunity was assessed on $35^{\text {th }}$ day of first immunization by lymphocyte proliferation assay. A single cell suspension of splenocytes at a concentration of $10^{6}$ cells/ml from 6 mice sacrificed in each group prepared in RPMI-1640 medium (Sigma-Aldrich) supplemented with 10\% fetal bovine serum was employed in the assay. Each well in duplicate received $50 \mu \mathrm{l}$ of $5 \mu \mathrm{g} / \mathrm{ml}$ whole cell antigen or $50 \mu \mathrm{l}$ of RPMI 1640 medium (negative control). The stimulation index (SI) was calculated as ratio of optical density (OD) of stimulated well and OD of negative control well.

\section{Challenge study and statistical analysis}

Twelve mice in each group were challenged with a lethal dose $\left(10 \mathrm{LD}_{50}\right)$ calculated by Reed and Muench (24) of virulent P. multocida B:2 (strain P52) culture by intraperitoneal route after 35 days of first immunization. The heart blood from each of the dead mice was collected and examined for the presence of P. multocida $\mathrm{B}: 2$ organisms.

Statistical analysis for IgG titre and SI was performed by ANOVA (analysis of variance) (Duncan's Post hoc test) whereas IgG subclass titres were analysed by T-test (29). The data of different immunological assays were expressed as mean \pm standard error (S.E.).

\section{RESULTS}

\section{PCR amplification and characterization of recombinant plasmids}

PCR amplification of $P$. multocida tbpA gene resulted in 
the product of size $\sim 2334$ bp and subsequently the recombinant pIRES-tbpA plasmid digested with restriction enzymes XhoI and $M l u \mathrm{I}$ revealed an insert release of identical size (Fig. 2a). PCR targeting IL2 gene using mice cDNA as template amplified a product of $\sim 500 \mathrm{bp}$ and restriction endonuclease analysis of recombinant pIRES-tbpA-IL2 construct with restriction enzymes SalI and NotI resulted in the release of $\sim 500$ bp insert, hence confirming the clone (Fig. 2b).

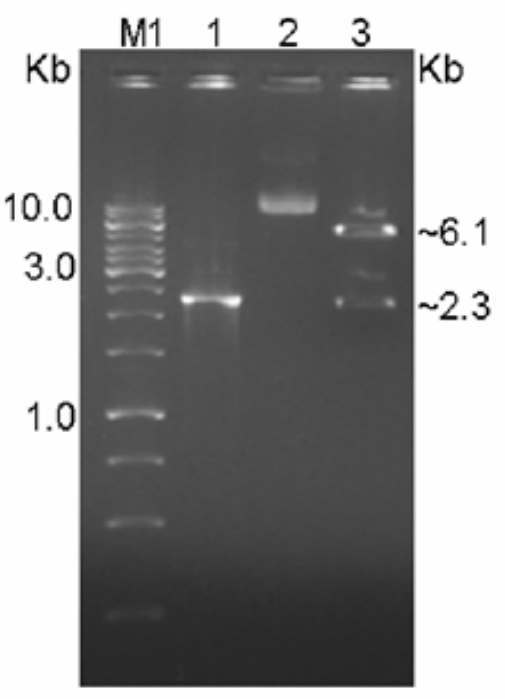

(a)

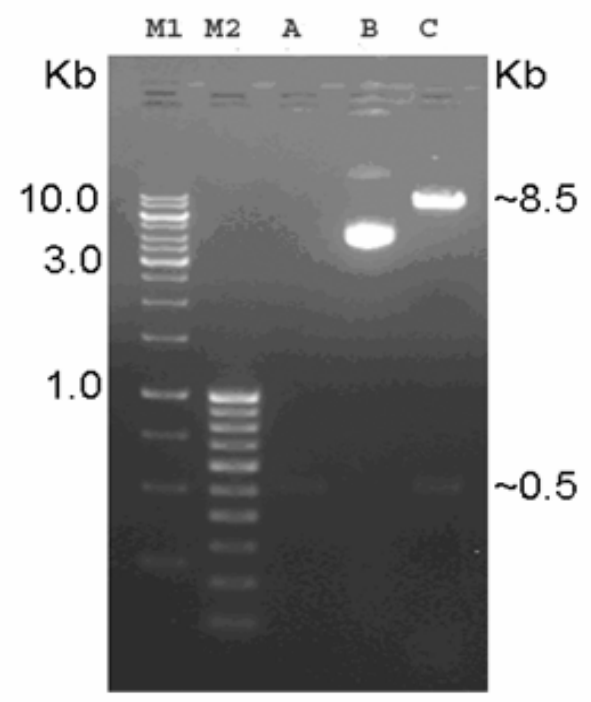

(b)

Figure $2 \mathbf{a} \& 2 \mathbf{b}$. PCR amplification of $t b p A$ gene of $P$. multocida \& murine $I L 2$ gene and restriction endonuclease analysis of pIRES-tbpA plasmid \& pIRES-tbpA-IL2 plasmid. Lane M1: 1 Kb DNA ladder. Lane 1: PCR amplified tbpA gene. Lane 2: Undigested pIRES-tbpA plasmid. Lane 3: Digested pIRES-tbpA clone showing insert release. Lane M2: 1 Kb DNA ladder. Lane M3: 100 bp DNA ladder. Lane A: PCR amplified IL2 gene. Lane B: Undigested pIRES-tbpA-IL2 plasmid. Lane C: Digested pIRES-tbpA-IL2 clone showing insert release.

\section{In vitro expression analysis}

The diffuse cytoplasmic green fluorescence was observed in MDCK cells transfected with recombinant pIRES-tbpA indicating the in vitro expression of tbpA protein (Fig. 3).

\section{Immune responses}

The ELISA titres observed in sera of mice immunized with various DNA vaccine constructs are depicted in Fig. 4. The maximum antibody titre among the groups injected with DNA vaccines only (Groups I and II) was observed in the group administered with pIRES-tbpA-IL2 (Group II). Further, primary immunization with pIRES-tbpA-IL2 followed by boosting with oil adjuvant vaccine (Group VI) produced antibody titres comparable to OAV group (Group III). The serum profiles of IgG subclasses (IgG1 and IgG2a) of various groups at different intervals revealed that OAV (Group III) elicited a prominent IgG1 response whereas immunization with DNA vaccines resulted in a balanced $\operatorname{IgG1/IgG2a}$ response (Fig. 5a and 5b).

As regards lymphocyte proliferation assay, a significant difference was observed in the stimulation index of vaccinated groups as compared to control groups indicating the enhanced cellular immune response against the recombinant plasmids (Fig. 6). 


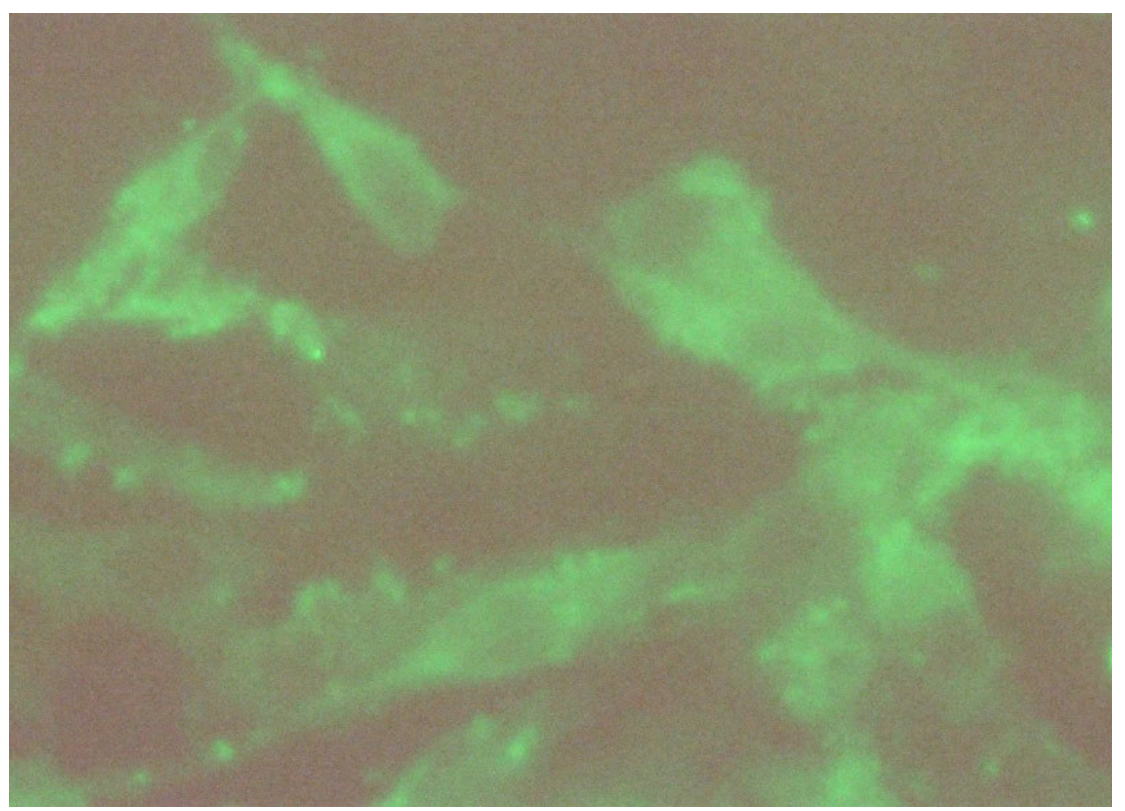

Figure 3. Expression analysis by IFAT in MDCK cells transfected with pIRES-tbpA. The green florescence emitted by the cells shows that the cells have started in vitro synthesis of recombinant tbpA after transfection.

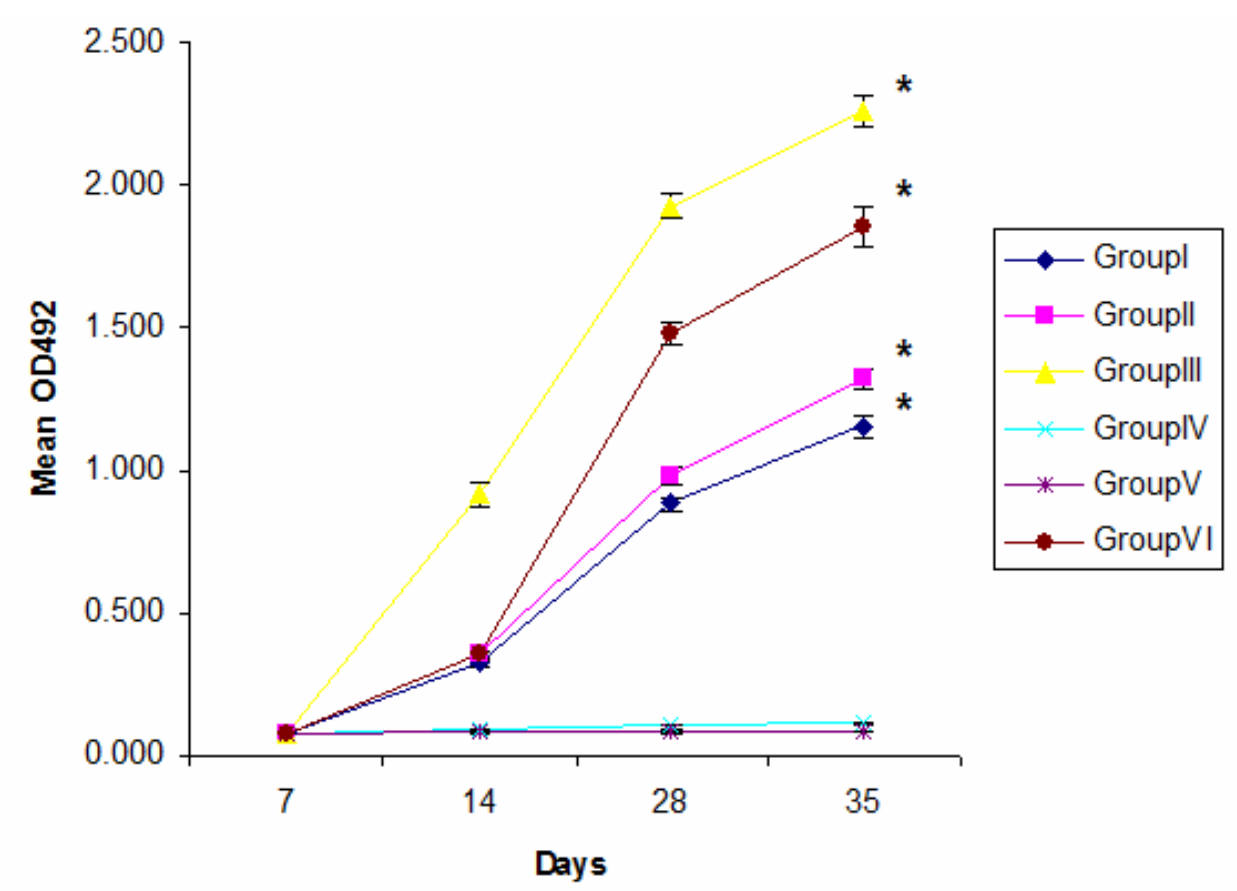

Figure 4. Serum antibody responses in immunized mice measured by indirect ELISA at different time intervals post immunization. The groups I, II, III, IV and V were administered pIRES-tbpA, pIRES-tbpA-IL2, oil adjuvant vaccine (OAV), pIRES vector and PBS, respectively, as primary as well as booster dose while the group VI was administered primary vaccination with pIRES-tbpA-IL2 and boosted with OAV. Each line represents mean O.D. \pm standard error of six pooled serum samples, each of which contained sera from three individual mice. $* P \leq 0.05$. 
IgG subclass titre at 14th day

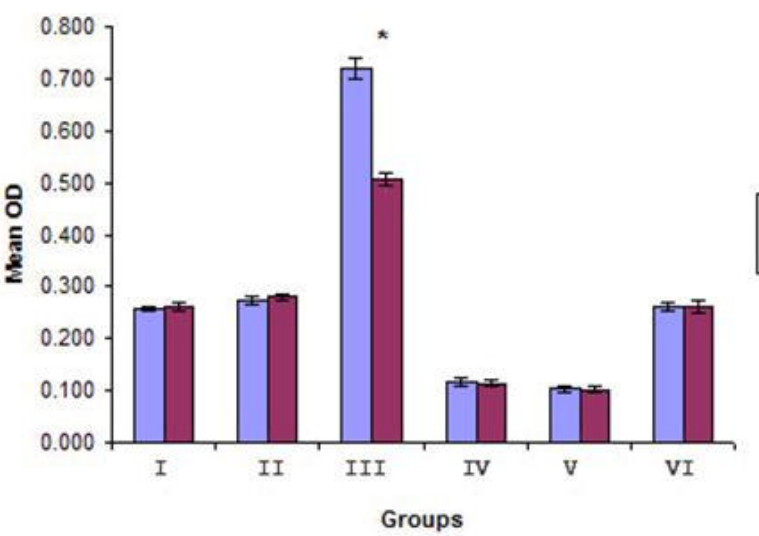

(a)
IgG subclass titre at 35 th day

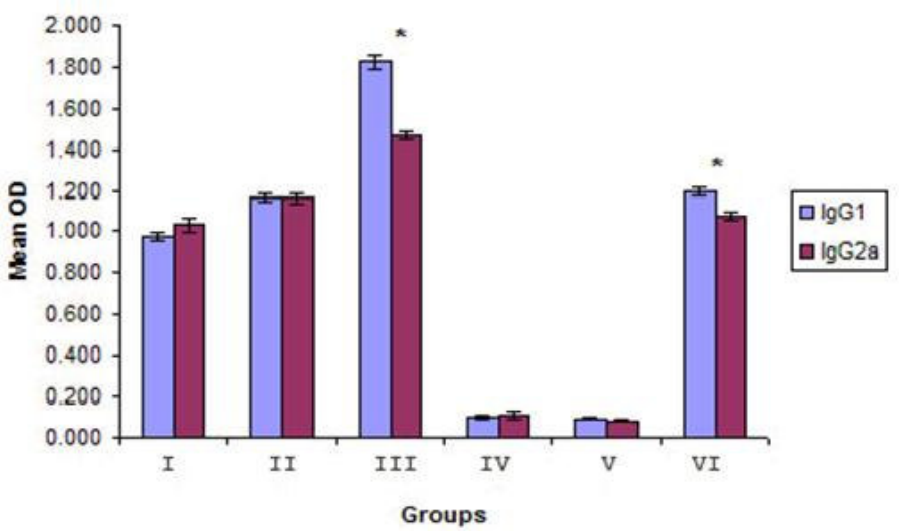

(b)

Figure 5a \& 5b. Serum IgG1 and IgG2a responses in immunized mice measured by indirect ELISA at $14^{\text {th }}$ day post immunization (a) and $35^{\text {th }}$ day post immunization (b). Each bar represents mean O.D. \pm standard error of six pooled serum samples, each of which contained sera from three individual mice. $* P \leq 0.05$.

Stimulation Indices of various groups at 35th day

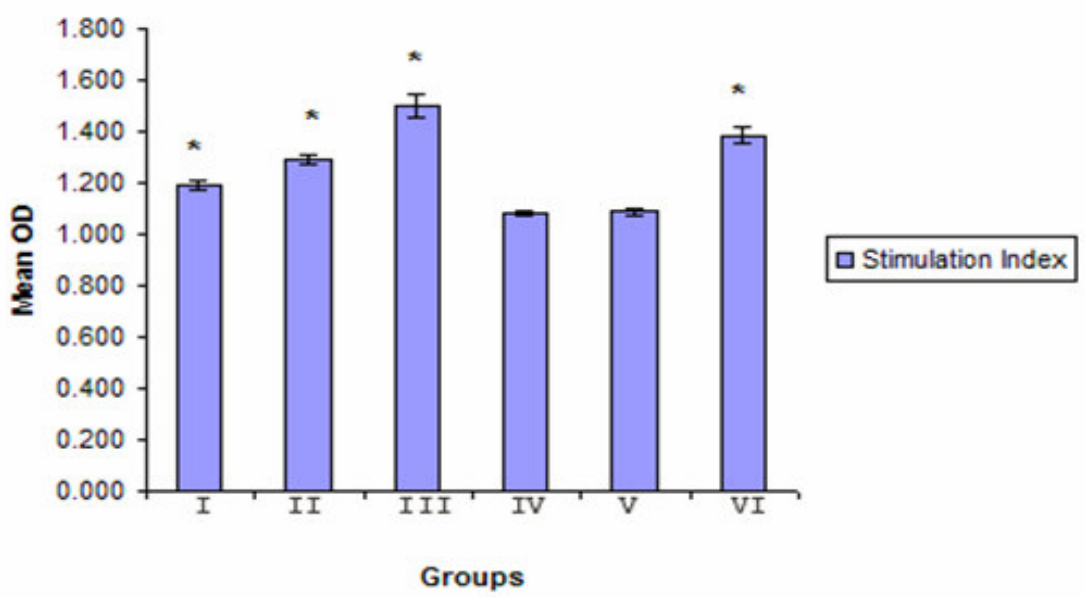

Figure 6. Splenic lymphocyte proliferative response by MTT assay in immunized mice at $35^{\text {th }}$ day. Each bar represents mean O.D. \pm standard error of stimulation index from six individual mice from each group. $* P \leq 0.05$.

\section{Challenge study}

Protection studies revealed that pIRES-tbpA provided partial protection $(50 \%)$ in mice against lethal challenge with virulent $P$. multocida culture (Table 1). However, incorporation of IL2 gene in vaccine (pIRES-tbpA-IL2) enhanced the protection levels significantly $(66.6 \%)$ in comparison to monocistronic vaccine.
Additionally, primary immunization with pIRES-tbpA-IL2 followed by a booster dose of OAV afforded almost equal protection to OAV group ( $75 \%$ and $83.3 \%$, respectively). All the animals in non-immunized and vector vaccinated control groups died within $48 \mathrm{hr}$ of challenge infection and causative organism was isolated from all the dead mice. 
Table 1. Protection afforded by various vaccines against challenge with $P$. multocida

\begin{tabular}{llcccc}
\hline S. No. & Group & $\begin{array}{c}\text { No. of mice } \\
\text { immunized }\end{array}$ & $\begin{array}{c}\text { No. of mice } \\
\text { challenged }\end{array}$ & $\begin{array}{c}\text { No. of mice } \\
\text { died following } \\
\text { challenge }\end{array}$ & $\begin{array}{c}\text { \% age } \\
\text { protection }\end{array}$ \\
\hline I & pIRES-tbpA & 18 & 12 & 6 & $50.0 \%$ \\
II & pIRES-tbpA-IL2 & 18 & 12 & 4 & $66.6 \%$ \\
III & Oil adjuvant & 18 & 12 & 2 & $83.3 \%$ \\
IV & vaccine (OAV) & 18 & 12 & 12 & $0 \%$ \\
V & pIRES vector & 18 & 12 & 12 & $0 \%$ \\
VI & PIRES-tbpA-IL2 & 18 & 12 & 3 & $75.0 \%$ \\
\hline
\end{tabular}

\section{DISCUSSION}

Iron regulated outer membrane proteins (IROMPs) particularly TbpA has been suggested as a vaccine candidate by researchers in various bacterial species viz. Pasteurella haemolytica, Neisseria meningitides, Haemophilus influenzae $(1,17,22)$. The rationale for targeting these antigens is that they are essential for overcoming the iron restriction imposed by the host iron binding protein transferrin and are accessible at the cell surface. Outer membrane antigens of $P$. multocida serotype B grown under iron limited conditions have been used as immunogens and shown to elicit homologous protection (13). West et al. (34) reported TbpA to afford protection against Neisseria meningitides challenge when administered as the sole immunogen and suggested that it could provide protection against a wider range of meningococcal strains.

Cytokine adjuvants have been used in the control of infectious diseases especially for the development of recombinant genetic vaccines and DNA vaccines (26). Infact, plasmids encoding cytokine antigens were suggested to be more efficient than the cytokine protein antigens themselves possibly due to consistent generation of more cytokines to enhance the immunity (37). In the recent past, modified IL2 alone in the form of DNA vaccine has been found to give $90 \%$ protection against virulent lethal $P$. multocida challenge (39).
The present study was designed to test immunogenic potential of $t b p A$ gene encoding transferrin binding protein $\mathrm{A}$ of $P$. multocida serotype B:2 as DNA vaccine. In order to enhance its immune response, a cytokine adjuvant IL2 gene from mice was incorporated in DNA vaccine. The cultured splenocytes were activated with Con $\mathrm{A}$, a potent $\mathrm{T}$ cell mitogen in order to enhance the expression of cytokine genes (20).

The $t b p A$ and murine IL2 genes were cloned in pIRES mammalian expression vector in such a way that the former was transcribed under cytomegalovirus promoter whereas the latter was under IRES (internal ribosome entry site) promoter from encephalomyocarditis virus. The pIRES-tbpA construct was tested for in vitro expression of protein by fluorescence testing in MDCK cells. The emission of green fluorescence from cells transfected with genetically engineered plasmid viz. pIRES-tbpA revealed that the TbpA protein expressed under the eukaryotic promoter retained its immunogenic nature. The use of IFAT for testing the expression of proteins encoded by recombinant plasmids has been reported previously also (16).

The immunization of mice with the pIRES-tbpA induced significantly higher antibody and cellular immune response as compared to PBS control. The DNA vaccine containing IL2 gene in addition to bacterial gene further enhanced the humoral and CMI responses reflecting the active role of IL2 in augmentation of immune response including the proliferation 
of activated lymphocytes. In the recent past, Gonza' lez-Smith et al. (9) have also observed enhanced immune responses to $\mathrm{Cu}-\mathrm{Zn}$ superoxide dismutase (SOD) when coexpressed with IL2. The mice immunized with the bicistronic plasmid pSecTag-SOD-IL2 showed increased resistance to challenge with Brucella abortus than those immunized with monocistronic pSecTag-SOD plasmid. The role of IL2 as immunomodulator when administered along with primary immunogen in vaccine preparations has been suggested by other workers also $(5,38)$.

Further, it was observed that primary vaccination with pIRES-tbpA-IL2 construct followed by boosting with OAV (Group VI) resulted in significant increase in humoral as well as CMI response. It could be explained by the fact that DNA vaccine priming leads to generation of strong antibody response along with the memory immune response and these memory cells elicit secondary immune response when booster dose comprising of target antigen is administered (14). The concept of enhancement of immune response upon boosting with the whole cell antigen after DNA priming has also been observed in Mycobacterium, where sequential immunization with DNA vaccine and bacilli Calmette-Guerin (BCG) was found more effective than BCG immunization alone in protecting against $M$. tuberculosis infection (28).

In order to get a clear perspective of immune response against various vaccine constructs, the serum titres of IgG1 and $\operatorname{IgG} 2 \mathrm{a}$ isotypes were also measured by ELISA. DNA vaccines produced a balanced $\operatorname{IgG} 1 / \operatorname{IgG} 2 \mathrm{a}$ response where as $\mathrm{OAV}$ generated predominantly IgG1 type of immune response. $\operatorname{IgG} 2 \mathrm{a}$ level is mainly dependent on IFN- $\gamma$ indicating a bias towards Th1 type of immune response, whereas IgG1 level correlate with the humoral immunity (Th2 type) (6). Hence, it suggested that OAV produced primarily humoral type of immune response whereas, immunity against DNA vaccine constructs was cellular and humoral types both. Mixed type of immune response has been reported by various workers in mice receiving DNA vaccine constructs $(4,18)$.

Similar to the enhancement of immune response, the incorporation of IL2 along with $t b p A$ in vaccine construct increased the protection levels also, which was in concordance with earlier reports $(11,39)$. Also, primary vaccination with pIRES-tbpA-IL2 followed by a booster dose of OAV produced almost equal protection as that of OAV, further emphasizing the importance of DNA priming and whole cell antigen boost strategies for increasing the protection levels (8). The lesser protection afforded by DNA vaccines alone implies the inability of single immunogen to protect against Pasteurella infections as the organism is antigenically intricate and molecular details of its pathogenicity are still not well established. Another reason for this could be lesser in vivo transfection efficiency with these vaccines. Various workers have observed the enhanced efficacy of DNA vaccines by increasing the dose or employing other methods of immunization like gene gun or electroporation $(27,33)$.

Further studies are required to identify and evaluate the other possible immunogens of $P$. multocida that could be administered along with tbpA gene in DNA vaccine preparations against the disease to enhance the efficacy of this vaccine.

\section{ACKNOWLEDGEMENTS}

The authors are grateful to the Director, Indian Veterinary Research Institute, Izatnagar and ICAR sponsored 'All India Network Program on Haemorrhagic Septicaemia' for providing facilities to conduct this study.

\section{REFERENCES}

1. Ala'Aldeen, D.A.A.; Borriello, S.P. (1996). The meningococcal transferrin-binding proteins 1 and 2 are both surface exposed and generate bactericidal antibodies capable of killing homologous and heterologous strains. Vaccine 14, 49-53. 
2. Bracci, L.; Canini, I.; Puzelli, S.; Sestili, P.; Venditti, M.; Spada, M.; Puzelli, S.; Donatelli, I.; Belardelli, F.; Proietti, E. (2005). Type I IFN as a vaccine adjuvant for both systemic and mucosal vaccination against influenza virus in mice and affects antigen capture at mucosal level. Vaccine 23, 2994-3004.

3. Chandrasekran, S.; Yeap, P.C.; Saad, R. (1987). Effect of storage conditions on the stability and potency of haemorrhagic septicaemia oil adjuvant vaccine. Kajian. Veterinar. 19, 71-75.

4. Chen, Y.L.; Wang, S.N.; Yang, W.J.; Chen, Y.J.; Lin, H.H.; Shiuan, D. (2003). Expression and immunogenicity of Mycoplasma hyopneumoniae heat shock protein antigen P42 by DNA vaccination. Infect. Immun. 71, 1155-1160.

5. Chow, Y.H.; Huang, W.L.; Chi, W.K.; Chu, Y.D.; Tao, M.H. (1997) Improvement of Hepatitis B Virus DNA Vaccines by Plasmids Coexpressing Hepatitis B Surface Antigen and Interleukin-2. J. Virol. 71, 169-178.

6. Coffman, R.L.; Lebman, D.A.; Rothman, P. (1993). Mechanism and regulation of immunoglobulin isotype switching. Adv. Immunol. 54, 229270

7. Confer, A.W.; Suckow, M.A.; Montelongo, M.; Dabo, S.M.; Miloscio, L.J.; Gillespie, A.J.; Meredith, G.L. (2001). Intranasal vaccination of rabbits with Pasteurella multocida A:3 outer membranes that express iron-regulated proteins. Am. J. Vet. Res. 62, 697-703.

8. Feng, C.G.; Palendira, U.; Demangel, C.; Spratt, J.M.; Malin, A.S.; Britton, W.J. (2001). Priming by DNA immunization augments protective efficacy of Mycobacterium bovis BCG against tuberculosis. Infect. Immun. 69, 4174-4176.

9. Gonza' lez-Smith, A.; Vemulapalli, R.; Andrews, E.; Oñ ate, A. (2006). Evaluation of Brucella abortus DNA vaccine by expression of $\mathrm{Cu}-\mathrm{Zn}$ superoxide dismutase antigen fused to IL-2. Immunobiol. 211, 65-74.

10. Hodgson, J.C.; Finucane, A.; Dagleish, M.P.; Ataei, S.; Parton, R.; Coote, J.G. (2005). Efficacy of vaccination of calves against hemorrhagic septicemia with a live aroA derivative of Pasteurella multocida B:2 by two different routes of administration. Infect. Immun. $73,1475-1481$.

11. Jianrong, L.; Xueya, L.; Yaowei, H.; Songshu, M.; Ronghui, X.; Ruitang, D.; Lian, (2004). Enhancement of the immunogenicity of DNA vaccine against infectious bursal disease virus by co-delivery with plasmid encoding chicken interleukin 2. Virology 329, 89-100.

12. Karlsson, K., Granstrom, M., Lindberg, A.A., 1986. Salmonella sp. antibodies In: Methods in Enzymatic Analysis. 3rd Ed. (Burgmeyer J. and Grabl, M., eds) vol. XI, Antigens and Antibodies. VCH. pp. 85-98.

13. Kennett, L.; Muniandy, N.; Mukkur, T.K.S. (1993). Comparative protection potential of non-living intact cells and purified outer membrane and associated proteins of Pasteurella multocida type 6: B grown under iron regulated conditions. In: Pasteurellosis in production animals. ACIAR Press, Canberra, Australia, p. 144-149.

14. Kowalczyk, D.W.; Ertl, H.C.J. (1999). Immune responses to DNA vaccines. Cell. Mol. Life Sci. 55, 751-770.

15. Liu, M.A. (2003). DNA vaccines: a review. J. Int. Med. 253, 402-410.

16. Liu, S.; Gonga, Q.; Wang, C.; Liu, H.; Wang, Y.; Guoa, S.; Wang, W.; Liu, J.; Shao, M.; Chi, L.; Zhaoa, K.; Wang, Z.; Shi, Y.; Huange, Y.; Guli, A.;Zhang, C.; Kong, X. (2008). A novel DNA vaccine for protective immunity against virulent Mycobacterium bovis in mice. Immunol. Lett. 117, 136-145.

17. Loosmore, S.M.; Yang, Y.P.; Coleman, D.C.; Shortreed, J.M.; England, D.M.; Harkness, R.E.; Chong, P.S.C.; Klein, M.H. (1996). Cloning and expression of the Haemophilus influenzae transferrin receptor genes. Mol. Microbiol. 19, 575-586.

18. Montesino, C.M.; Andrews, E.; Rivers, R.; González-Smith, A.; MoragaCid, G.; Folch, H.; Céspedes, S.; Oñate, A.A. (2004). Intraspleen delivery of a DNA vaccine coding for superoxide dismutase (sod) of Brucella abortus induces SOD-specific CD4+ and CD8+ T cells. Infect. Immun. 72, 2081-2087.

19. Ogunnariwo, J.A.; Schryvers, A.B. (2001). Characterization of a novel transferrin receptor in bovine strains of Pasteurella multocida. J. Bacteriol. 183, 890-896.

20. Okamoto, T.; Kobayashi, T. (1997). Effects of concanavalin A on cytokine mRNA expression in mouse liver. Jpn. J. Pharmacol. 75, 199201.

21. Penn, C.W.; Nagy, L.K. (1976). Isolation of protective non-toxic capsules antigen from Pasteurella multocida types B and E. Res. Vet. Sci. 20, 90-96.

22. Potter, A.A.; Schryvers, A.B.; Ogunnariwo, J.A.; Lo, R.Y.C.; Watts, T. (1999). Protective capacity of Pasteurella haemolytica transferrinbinding proteins TbpA and TbpB in cattle. Microb. Pathog. 27, 197-206.

23. Qiu, J.T.; Chang, T.C.; Lin, C.T.; Chen, Y.M.; Li, F.Q.; Soong, Y.K.; Lai, C.H. (2007). Novel codon-optimized GM-CSF gene as an adjuvant to enhance the immunity of a DNA vaccine against HIV-1 Gag. Vaccine 25, 253-263.

24. Reed, L.J.; Muench, H. (1938). A simple method for estimating 50 per cent end point. Am. J. Hyg. 27, 493-497.

25. Rimler, R.B. (2001). Purification of a cross-protective antigen from Pasteurella multocida grown in vitro and in vivo. Avian Dis. 45, 572-80.

26. Sato, Y.M.; Roman, H.; Tighe, D.; Lee, M.; Corr, M.D.; Nguyen, G.J.; Silverman, M.L.; Dennis, A.; Carson, E.R. (1996). Immunostimulatory DNA sequences necessary for effective intradermal gene immunization. Science 273, 352-354.

27. Shiau, Y.T.; Huang, Y.H.; Wu, J.C.; Tao, M.H.; Syu, W. Jr; Chang, F.Y.; Lee, S.D. (2006). Analysis of humoral immunity of hepatitis D virus 
DNA vaccine generated in mice by using different dosage, gene gun immunization, and in vivo electroporation. J. Chin. Med. Assoc. 69, 7-13.

28. Skinner, M.A.; Buddle, B.M.; Wedlock, D.N.; Keen, D.; Lisle, G.W.; Tascon, R.E. (2003). A DNA prime-BCG boost vaccination strategy in cattle induces protection against bovis tuberculosis. Infect. Immun. 71, 4901-4907.

29. Snedecor, G.; Cochran, W.; Cox, D. (1989). In: Statistical Methods (8th edition). The Iowa State University Press.

30. Srivastava, S.K. (1998). Immunogenicity of Pasteurella multocida grown in iron restricted medium. J. Appl. Anim. Res. 13, 137-144.

31. Tabatabaei, M.; Liu, Z.; Finucane, A.; Parton, R.; Coote, J. (2002). Protective immunity conferred by attenuated aroA derivatives of Pasteurella multocida B:2 strains in a mouse model of hemorrhagic septicemia. Infect and Immun. 70, 3355-3362.

32. Veken, J.W.; Shah, N.H.; Klaasen, P.; Oudega, B.; DeGraaf, F.K. (1996) Binding of host iron-binding proteins and expression of iron-regulated membrane proteins by different serotypes of Pasteurella multocida causing haemorrhagic septicaemia. Microb. Pathog. 21, 59-64.

33. Wang, S.; Zhang, C.; Zhang, L.; Li, J.; Huang, Z.; Lu, S. (2008). The relative immunogenicity of DNA vaccines delivered by the intramuscular needle injection, electroporation and gene gun methods. Vaccine 26, 2100-2110.
34. West, D.; Reddin, K.; Matheson, M.; Heath, R.; Funnell, S.; Hudson, M.; Robinson, A.; Gorringe, A. (2001). Recombinant Neisseria meningitides transferrin binding protein A protects against experimental meningococcal infection. Infect. Immun. 69, 1561-1567.

35. Williman, J.; Lockhart, E.; Slobbe, L.; Buchan, G.; Baird, M. (2006). The use of Th1 cytokines, IL-12 and IL-23, to modulate the immune response raised to a DNA vaccine delivered by gene gun. Vaccine 24, 4471-4474.

36. Wu, Jin-Ru; Jui-Hung, S.; Happy, K.S.; Chih-Feng, C.; Poa-Chun, C. (2007). Protective immunity conferred by recombinant Pasteurella multocida lipoprotein E (PlpE). Vaccine 25, 4140-4148.

37. Wu, M.; Gao, R.; Meng, M.; Li, J.; Tan, M.; Shen, Y.; Wang, L.; Yin, X.; Wu, X.; Xie, H.; Liu, S. (2004). Regulating effects of pig interleukin6 gene and $\mathrm{CpG}$ motifs on immune responses to pig trivalent vaccines in mice. Res. Vet. Sci. 77, 49-57.

38. Xu, C.; Li, Z.S.; Du, Y.Q.; Gong, Y.; Yang, H.; Sun, B.; Jin, J. (2007). Construction of recombinant attenuated Salmonella typhimurium DNA vaccine expressing H. pylori ureB and IL-2. World J. Gastroenterol. 14, 939-944.

39. Zhao, X.; Li, H.; Chen, J.; Zhang, H.; Wang, Y.; Chen, Q.; Zhao, Z.; Cheng, C.; Zhang, H.; Yang, Y.; Wang, H.; Gao, R. (2007). Shuffling of pig interleukin-2 gene and its enhancing of immunity in mice to Pasteurella multocida vaccine. Vaccine 25, 8163-8171. 